\title{
What can naturally occurring mutations tell us about the pathogenesis of COPD?
}

\author{
S J Marciniak, D A Lomas
}

Department of Medicine, University of Cambridge, Cambridge Institute for Medical Research, Cambridge, UK

Correspondence to:

Dr S J Marciniak, Department of Medicine, University of

Cambridge, Cambridge Institute for Medical Research, Wellcome Trust/MRC Building, Hills Road,

Cambridge CB2 OXY, UK; sjm20@cam.ac.uk

Received 20 March 2008 Accepted 14 July 2008

\section{ABSTRACT}

The airway and emphysema phenotypes of chronic obstructive pulmonary disease (COPD) cluster in susceptible families. Some of this clustering is likely to be the result of shared genetic factors. There are a number of relatively rare syndromes that predispose to COPD, and a growing number of association and linkage studies that have assessed the genetic factors that predispose smokers to airflow obstruction. A review of the literature was performed to determine what has been learnt about the factors and pathways that predispose some individuals to progressive airflow obstruction while others are relatively resistant. There is very strong evidence that the integrity of the extracellular matrix, and in particular the elastin fibres, are important in the pathogenesis of COPD. There is also support for the role of proteinaseantiproteinase imbalance and probably oxidative stress. However, many of the genetic studies have focused on pathways that have already been implicated in disease. It is now essential that future studies take advantage of multiple large cohorts that have been phenotyped for both airways disease and emphysema, and use modern technology to perform unbiased genome-wide analyses of genetic variation in COPD. Only then will we have new insights into the pathways that underlie this common condition.

Human diseases can be deceptively complex. The pathogenesis of some of the commonest conditions remains obscure. An excellent example is chronic obstructive pulmonary disease (COPD); while we know that COPD is caused by inhaled smoke, remarkably few smokers develop airflow obstruction. It is hoped that, by understanding the genetics that underlie this disease, we may be able to tease apart its basic biology and identify new therapeutic avenues. Familial clustering suggests that heritable factors may play a role in the development of COPD. ${ }^{12}$ Indeed, a recent study has shown that both the airway and emphysema components cluster independently, suggesting that different genetic factors play a role in the development of these two components of the disease. ${ }^{3}$ However, apart from the relatively uncommon $\alpha_{1^{-}}$ antitrypsin mutations which account for $1-2 \%$ of cases, the additional genetic factors remain obscure.

In this review we examine the current literature to identify likely candidate genes in order to understand better the pathogenesis of this important disease. We set out by searching the PubMed database with the terms "(COPD OR emphysema) AND (genetic OR mutation OR polymorphism)" on 10 February 2008 and obtained 1071 hits. These titles and abstracts were screened and relevant papers were obtained for detailed assessment. Their bibliographies were also screened for additional sources. Where possible, we have given special emphasis to studies in which COPD was diagnosed using standardised spirometric criteria; cases and control groups were appropriately matched for both smoking and ethnicity and where alleles were shown to be in HardyWeinberg equilibrium (HWE) in the control group.

In genetic association studies it is common to consider a statistical significance level of $<0.05$ to be "noteworthy", but one should be wary. It has been shown that many genetic association studies report false positive findings owing to a failure to appreciate the prior probability of an association and the power of the study to detect a meaningful effect. ${ }^{4}$ When the prior probability of an association is low-that is to say, when there is little functional or epidemiological data to support an association - the numbers of subjects required to guard against a false positive result increases. Consequently, the identification of a genetic association in a single study must always be treated with caution and in our review we have concentrated on replicated results (table 1).

\section{EXTRACELLULAR MATRIX}

Alveolar tissue consists of epithelial cells, capillaries and extracellular matrix (ECM), the latter comprising a complex network of scaffolding proteins, principally elastin and collagen. The elastin filaments form from tropoelastin monomers that selfassemble into aggregates and then fuse with microfilaments. Multiple covalent cross-links between the lysines in neighbouring filaments provide stability. Cutis laxa is a family of autosomal dominant (OMIM \#123700), X-linked (OMIM \#304150) and recessive (OMIM \#219100, 219200) human diseases characterised by excessively slack connective tissues. Several families with the milder autosomal dominant form show early-onset pulmonary pathology including emphysema, particularly if inherited with the Z allele of $\alpha_{1}$-antitrypsin. ${ }^{5}$ Two groups independently identified separate mutations within the ELN (elastin) gene that cause mild cutis laxa and early onset COPD. ${ }^{67}$ The ELN gene maps to $7 \mathrm{q} 11.23$ in man but, as chromosome 7 has not been identified in linkage analysis as a site associated with COPD, it is likely that $E L N$ mutations are a rare cause of this disease.

Elastin fibres bind other proteins including fibulins which, in turn, bind multiple ECM components and the basement membrane. The fibulins are a family of six proteins, at least two of which are mutated in severe autosomal recessive 
Table 1 Candidate COPD genes

\begin{tabular}{|c|c|c|c|c|c|}
\hline Symbol & Name & Locus & Function & $\begin{array}{l}\text { References } \\
\text { for }\end{array}$ & $\begin{array}{l}\text { References } \\
\text { against }\end{array}$ \\
\hline$E L N$ & Elastin & $7 q 11$ & Matrix & $5-7$ & \\
\hline FBLN4 & Fibulin 4 & $11 q 13$ & Matrix & 8 & \\
\hline FBLN5 & Fibulin 5 & $14 q 32$ & Matrix & 9 & \\
\hline FBN1 & Fibrillin & $15 q 21$ & Matrix & $10-12$ & \\
\hline ATP7A & Copper transporter & $\mathrm{Xq13}$ & Matrix & 13 & \\
\hline TGFB1 & $\begin{array}{l}\text { Transforming growth } \\
\text { factor } \beta 1 \text { (TGF } \beta 1 \text { ) }\end{array}$ & $19 q 13$ & Matrix & $14-18$ & 19 \\
\hline LTBP4 & $\begin{array}{l}\text { Latent TGF } \beta \text { binding } \\
\text { protein } 4\end{array}$ & $19 q 13$ & Matrix & 21 & \\
\hline SERPINA1 & $\alpha_{1}$-Antitrypsin & $14 q 32$ & Anti-protease & $23-25,75-77$ & \\
\hline SERPINE2 & Serpin E2 & $2 q 33$ & Antiprotease & 26,27 & 28 \\
\hline TIMP2 & $\begin{array}{l}\text { Tissue inhibitor of } \\
\text { metalloproteinase } 2\end{array}$ & $17 q 25$ & Antiprotease & 34 & \\
\hline MMP1 & Metalloproteinase 1 & $11 \mathrm{q} 22$ & Protease & 32 & 33 \\
\hline MMPg & Metalloproteinase 9 & $20 q 11$ & Protease & $29-31,33$ & 32 \\
\hline MMP12 & Metalloproteinase 12 & $11 q 22$ & Protease & 32 & \\
\hline$E P H X 1$ & Epoxide hydrolase 1 & $1 q 42$ & Detoxification & $\begin{array}{l}17,35-42,44, \\
46-48\end{array}$ & 43,45 \\
\hline GST-P1 & $\begin{array}{l}\text { Glutathione S-transferase } \\
\text { P1 }\end{array}$ & $11 q 13$ & Detoxification & $48-50$ & 44,51 \\
\hline GST-M1 & $\begin{array}{l}\text { Glutathione S-transferase } \\
\text { M1 }\end{array}$ & $1 \mathrm{p} 13$ & Detoxification & 37 & 45 \\
\hline HMOX1 & Heme oxygenase 1 & $22 q 13$ & Detoxification & $38,39,52-55$ & 50,54 \\
\hline SOD3 & Superoxide dismutase 3 & $4 p 15$ & Detoxification & 56,57 & \\
\hline$T N F$ & Tumour necrosis factor & $6 \mathrm{p} 21$ & Inflammation & $39,58,78-80$ & $42,47,59-68$ \\
\hline$G C$ & $\begin{array}{l}\text { Group specific } \\
\text { component }\end{array}$ & $4 q 12$ & Inflammation & $69-73$ & 74 \\
\hline
\end{tabular}

forms of cutis laxa and whose phenotype often includes earlyonset emphysema. ${ }^{89}$ A novel mutation in the fibulin-4 gene (FBLN4; 11q13) was recently identified in autosomal recessive cutis laxa with developmental emphysema. ${ }^{8}$ The mutation caused an amino acid substitution in an epidermal growth factor (EGF)-like domain of fibulin-4, leading to very low levels of extracellular protein. In a consanguineous Turkish family, a homozygous mutation in the related fibulin-5 gene (FBLN5; 14q32.1) was also found to cause cutis laxa and emphysema complicated by recurrent pulmonary infections. ${ }^{9}$ Once again, the mutation was located within an EGF-like domain, suggesting these are critical for fibulins to maintain the integrity of the ECM within the lung. Interestingly, analogous mutations in fibrillin, which bears homology to the fibulins, cause Marfan's syndrome. Moreover, mutations of fibrillin (FBN1; 15q21.1) have been described in neonatal Marfan's syndrome with very early-onset emphysema. ${ }^{10-12}$

Menkes disease (OMIM \#309400), characterised by abnormal hair and dysmorphic features, is caused by mutations in an intracellular copper transporter (ATP7A; Xq13.3). The clinical features are due to defective connective tissue synthesis believed to be the result of dysfunction of lysyl oxidase. This copperdependent enzyme is required for proper cross-linking of both collagen and elastin fibres. A recent case report described a child with Menkes disease and severe bilateral pan-lobular emphysema who died aged only 14 months. ${ }^{13}$ Gene sequencing revealed a splice-site mutation in $A T P 7 A$, suggesting that proper ECM cross-linking is vital for stability of the lung parenchyma.

In contrast to animal models of COPD, mutations in collagen have not been identified in humans. This does not appear to be due to an incompatibility of mutated collagen with survival as numerous collagen mutations have been described that cause other human diseases. Instead, it may reflect a more important role for elastin integrity in emphysema in humans than in mice. However, aberrant collagen synthesis has been implicated in COPD. The signalling molecule transforming growth factor $\beta 1$ (TGF $\beta 1$ ) enhances collagen synthesis in vivo, and polymorphisms in its gene (TGFB1; 19q13.1) have been associated with COPD,${ }^{14-18}$ although a recent large study found no association between TGFB1 polymorphisms and the rate of lung function decline in smokers. ${ }^{19}$ Intriguingly, the TGF $\beta 1$ gene maps to a locus on chromosome 19 which has high linkage (LOD 3.3) with forced expiratory volume in $1 \mathrm{~s}\left(\mathrm{FEV}_{1}\right)$ in smokers. ${ }^{15}{ }^{20}$ However, as is frequently the case with polymorphism studies, the literature is unclear. For example, two TGFB1 single nucleotide polymorphisms (SNPs) —rs1800469 and rs1982073-were found to be independently associated with COPD in two studies ${ }^{14} 17$ but, in another, they were only significant when analysed as part of a haplotype (combination of alleles) while yet another SNP, rs6957, was significant in its own right. ${ }^{18}$ Detailed analysis of the Boston Early-Onset COPD Study data revealed further complexity. ${ }^{15}$ While some alleles of TGFB1 were associated with $\mathrm{FEV}_{1}$ (rs2241712, rs2241718, rs6957), there was a separate but partially overlapping set of alleles associated with airflow obstruction (rs2241712, rs1800469, rs1982073). TGF $\beta 1$ protein is inactive when first secreted owing to the presence of an inhibitory $\mathrm{N}$ terminal pro-peptide. It is secreted in association with latent TGF $\beta 1$ binding proteins (LTBP) which share structural features with fibrillins and are assembled into the ECM. Mice with mutations in LTBP4 develop severe emphysema. ${ }^{21}$ Intriguingly, the sole study that has addressed LTBP4 (19q13.1-q13.2) polymorphisms found an association with COPD in man. ${ }^{17}$

Taken together, these studies provide strong evidence in support of a crucial role for the loss of ECM integrity-in 
particular the elastic components-in the development of COPD. It is therefore important to consider the enzymes implicated in degradation of the ECM.

\section{PROTEASE-ANTIPROTEASE BALANCE}

The protease-antiprotease theory has its roots in the observation that individuals with $\alpha_{1}$-antitrypsin are particularly susceptible to COPD and in experimental models of emphysema from the 1960s. This theory suggests that the pathogenesis of COPD and emphysema is the result of an imbalance between enzymes that degrade the ECM within the lung and proteins that oppose this proteolytic activity. Many proteases play important roles in remodelling or inflammation within the lung. It is essential that they are controlled by antiproteases to protect against uncontrolled degradation of the ECM.

The best understood example of genetically-induced emphysema results from mutations in the $\alpha_{1}$-antitrypsin gene (SERPINA1; 14q32.1). These increase the propensity of the protein to form ordered polymers which are incapable of inhibiting its target enzyme, neutrophil elastase. This abnormal behaviour leads to retention of the protein within hepatocytes as Periodic Acid Schiff positive inclusions and results in plasma deficiency of an important protease inhibitor (OMIM \#107400). It is now increasingly recognised that mutant $\alpha_{1}$ antitrypsin can also form polymers within the interstitium and alveolar spaces of the lung. These polymers are chemotactic for neutrophils and so combine with the deficiency of $\alpha_{1}$ antitrypsin to focus and amplify the inflammatory response within the lung. ${ }^{22}$ In most Northern European populations the frequency of the most severe $Z$ allele is about $1 / 2000$. Classically, $Z \alpha_{1}$-antitrypsin homozygotes carry the Glu342Lys mutation and suffer from early-onset emphysema when compared with individuals with normal $M M \alpha_{1}$-antitrypsin. The onset and progression of emphysema is markedly accelerated by cigarette smoking. Moreover, it appears that even a single allele of $Z \alpha_{1}$-antitrypsin may increase the risk of COPD. In the longitudinal Copenhagen City Heart Study the $M Z \alpha_{1}$ antitrypsin genotype increased the rate of decline of $\mathrm{FEV}_{1}$ by $19 \%$ compared with those who were MM homozygotes, causing a $30 \%$ increased risk of obstructive lung function and a $50 \%$ increased risk of physician-diagnosed COPD. ${ }^{23}$ The authors found that the frequency of the $M Z$ genotype in their Danish population was as high as $5 \%$ and calculated that it would account for $2.4 \%$ of cases of COPD. This is in contrast to the ZZ genotype which was causal in only $0.8 \%$ of cases. In meta-analysis, heterozygosity for the $Z$ allele carried an odds ratio for COPD of $2.31{ }^{24}$ In one study the MZ (but not MS; the $\mathrm{S}$ allele has the Glu264Val mutation) $\alpha_{1}$-antitrypsin genotype was associated with a rapid decline in $\mathrm{FEV}_{1}$ which was even more marked if there was also a family history of COPD, suggesting an interaction with additional genetic factors. ${ }^{25} \mathrm{~A}$ further meta-analysis combining 17 studies found a threefold increase in COPD in SZ $\alpha_{1}$-antitrypsin heterozygotes and a small increase in MS $\alpha_{1}$-antitrypsin heterozygotes.

Other pulmonary serine protease inhibitors may also be involved in the pathogenesis of COPD. Following earlier linkage studies demonstrating an association between chromosome $2 q$ and COPD, expression profiling of genes within that locus identified SERPINE2 (2q33-q35) as being upregulated during murine lung development and in the lungs of individuals with COPD. ${ }^{26}$ The authors went on to demonstrate an association between SNPs in SERPINE2 and COPD. SERPINE2 SNPs were found to segregate with COPD in a large multicentre familybased study and to be associated with COPD in a case-control analysis. ${ }^{27}$ However, another large study failed to replicate the association with COPD despite having adequate power. ${ }^{28}$ The latter study included individuals with COPD with and without emphysema, while the studies by DeMeo and colleagues ${ }^{26}$ included a preponderance of patients with emphysema assessed for lung volume reduction surgery. Nevertheless, while these differences may reflect different COPD phenotypes, they illustrate the need to replicate the findings of genetic association studies in multiple populations before drawing firm conclusions.

Since mutations of $\alpha_{1}$-antitrypsin so clearly lead to emphysema, one might infer that its target, neutrophil elastase, is central to the pathogenesis of disease. However, mutations in this protease have not been shown to be important, despite being studied extensively in other conditions. Instead, most evidence implicates matrix metalloproteinases (MMPs) in the pathogenesis of COPD. These are zinc-dependent endopeptidases involved in the degradation of many ECM components. An SNP of MMPq (20q11) was associated with COPD in Japanese $^{29}$ and Chinese ${ }^{30}$ populations; however, a further Japanese study found an association with emphysema distribution rather than with COPD per se. ${ }^{31}$ Another large study failed to show an association of $M M P 9$ with COPD, but instead MMP1 (11q22) and MMP12 (11q22) polymorphisms were identified. ${ }^{32}$ More recently, further data supporting a role for MMP9-but not MMP1-polymorphisms have been published. ${ }^{33}$ Tissue inhibitors of metalloproteinases (TIMPs) inhibit the MMPs but, thus far, only one polymorpism in TIMP2 (17q25) has been associated with COPD. ${ }^{34}$

\section{REACTIVE OXYGEN SPECIES}

Cigarette smoke contains vast numbers of free radicals that impose an oxidative stress on the lung. Such stress is believed to induce damage through multiple mechanisms, including direct oxidation of cellular lipids and DNA, and through inactivation of key proteins such as $\alpha_{1}$-antitrypsin. For this reason, much work has gone in to assessing the role of endogenous antioxidant enzymes in protecting against smoke-induced lung damage.

Many toxins in cigarette smoke are subject to first pass metabolism in the liver. Among the many enzymes involved, microsomal epoxide hydrolase (EPHX1; 1q42.1) has been intensely studied in the context of COPD. Several EPHX1 SNPs have been described that affect its activity. One of these leads to a $40 \%$ loss of in vitro activity (Tyr113His, the "slow" allele), while another increases activity by 25\% (His139Arg, the "fast" allele). In 1997 the "slow" variant of EPHX1 was found to increase the risk of emphysema by a staggering odds ratio of 5.0 and of COPD by an odds ratio of $4.1 .^{35}$ Since then, numerous studies have attempted to reproduce this effect with varying success. ${ }^{1736-46}$ Contradicting that original study, a recent systematic meta-analysis found homozygosity for the "slow" (Tyr113His) allele to be protective against COPD (odds ratio 0.5). ${ }^{47}$ This paradoxical result was possible only because five of the eight studies identified by those authors (including the 1997 study by Smith and Harrison) 353641445 were excluded on the grounds that alleles in the control group failed to show HWE. HWE refers to the expected distribution of genotypes in a stable population; deviation suggests either a systematic defect in genotyping or an unidentified bias in the selection of subjects. The failure to consider HWE in many studies is an important pitfall in population genetics and is all too common in studies of COPD. It would be fair to say that, despite the considerable effort invested in EPHX1, the role of its alleles in COPD remains 
unclear. Work on this gene continues and a recent analysis of the National Emphysema Treatment Trial (NETT) dataset has suggested a role for EPHX1 polymorphism in both the severity of COPD and the distribution of emphysema. ${ }^{48}$

Glutathione S-transferase (GST) comprises a large family of enzymes capable of catalysing the conjugation of reduced glutathione to endogenous and xenobiotic electrophilic compounds. The GSTs are important in the detoxification of many compounds and are highly polymorphic. These polymorphisms have been linked to susceptibility to toxins and carcinogens. SNPs in GSTP1 have been associated with COPD, ${ }^{49}$ the distribution of emphysema ${ }^{48}$ and more rapid decline in lung function. ${ }^{50}$ However, the data should be interpreted with caution as the third of the cohorts ${ }^{50}$ has been used in multiple analyses $^{42}$ and there was a lack of HWE for GSTP1 in their population. Moreover, no convincing association was found in other studies. ${ }^{44} 51$ The null mutation of GSTM1 (1p13.1) has also been associated with $\mathrm{COPD},{ }^{37}$ but others have failed to reproduce this finding. ${ }^{45}$

Heme oxygenase catalyses the first step in heme degradation. Heme oxygenase 1 (HMOX1; 22q13.1) is the inducible isoform that can be upregulated by a wide range of stresses. Bile pigments generated by heme cleavage are believed to have antioxidant properties, thus $H M O X 1$ induction is protective during cellular oxidant injury and overexpression of HMOX1 in lung tissue protects against hyperoxia. The HMOX1 gene 5'flanking region contains stretches of GC repeats that are highly polymorphic in length. Yamada and colleagues found a higher proportion of long repeats in patients with COPD and also showed that long repeats were associated with impaired promoter activity. ${ }^{52}$ Attempts to reproduce this effect have had varied success. ${ }^{38} 505354$ In one study an attempt was made to replicate the association in both a case-control study and family-based study. ${ }^{39}$ Confusingly, in the case-control study an association was seen between COPD and 30 but not 31 GC repeats, while in the family study the association was seen with the GC31 allele. While HMOX1 GC repeat length has not convincingly been shown to be associated with developing COPD, there are some data to support an association between the long allele and increased severity of disease..$^{55}$

Superoxide dismutase (SOD) is an important antioxidant enzyme that catalyses the conversion of superoxide to oxygen and hydrogen peroxide. The extracellular isoform (SOD3; 4p15) is abundant in lung parenchyma. In the cross-sectional Copenhagen Heart Study, the R213G allele that results in higher plasma levels was associated with significantly less COPD in smokers. ${ }^{56} \mathrm{~A}$ second study found similar results for the SOD3 isoenzyme, but not for other forms of SOD. ${ }^{57}$

While biologically very plausible, current genetic evidence fails to provide clear support for the involvement of detoxifying enzymes in the pathogenesis of COPD. Since the potential list of candidates to detoxify cigarette smoke remains long, it would be preferable if future studies were to take an unbiased approach to target identification rather than the current vogue for studying small numbers of candidate genes.

\section{INFLAMMATION}

Tumour necrosis factor $\alpha$ (TNF; 6p21) is a multifunctional cytokine whose levels are increased in bronchoalveolar lavage fluid, induced sputum samples and biopsies from patients with COPD. It is a plausible candidate gene for susceptibility to inflammatory disease, especially as well studied promoter polymorphisms clearly alter expression levels. Consequently, considerable effort has been invested into determining whether the promoter polymorphism in TNF $\alpha$ also predisposes smokers to COPD. Much interest was generated when an early study revealed an association (with a staggering odds ratio of over 10) between allele 2 and "bronchitis" in Taiwanese men. ${ }^{58}$ This study is difficult to interpret as a third of the men were "never smokers". Subsequent studies have found little evidence that TNF polymorphisms are associated with or modify the progression of COPD. ${ }^{42} 47$ 59-68

Group specific component (GC; 4q12), also known as vitamin $\mathrm{D}$ binding globulin, is a multifunctional protein that enhances the neutrophil and monocyte chemotactic activity of complement component $5 \mathrm{a}$. It is a highly polymorphic protein with more than 124 forms, although three (Gc*1F, Gc*1S and Gc2) make up the majority. Kueppers and colleagues found Gc2 homozygotes to be protected from COPD. ${ }^{69}$ Others have seen this protective effect, ${ }^{70}{ }^{71}$ while Gc*1F homozygosity has been found to be associated with COPD. ${ }^{72}{ }^{73}$ However, a much larger recent study has failed to reproduce these associations. ${ }^{74}$

Once again, a biologically plausible pathway has failed to yield unequivocal supportive genetic evidence of association with susceptibility to COPD. The complexity of innate and acquired immunity makes inflammation a far less attractive target for the candidate gene approach in studying COPD than was smoke detoxification. Only an unbiased approach is sufficiently robust to resolve this question.

\section{CONCLUSIONS}

Despite enormous efforts invested into understanding the genetics of COPD, most findings support the existing models of ECM integrity, protease/antiprotease balance and probably oxidative stress. It is now essential that future studies take advantage of multiple large cohorts that have been phenotyped for both airways disease and emphysema, ${ }^{3}$ and use modern technology to perform unbiased genome-wide analyses of genetic variation in COPD. Only then will we be able to identify novel pathways that are important in the initiation and progression of this disabling disease.

Funding: This work was supported by the Medical Research Council (UK), the Wellcome Trust and the Papworth NHS Trust. SJM is an MRC Clinician Scientist.

Competing interests: None.

\section{REFERENCES}

1. Silverman EK, Chapman HA, Drazen JM, et al. Genetic epidemiology of severe, early-onset chronic obstructive pulmonary disease. Risk to relatives for airflow obstruction and chronic bronchitis. Am J Respir Crit Care Med 1998;157:1770-8.

2. McCloskey SC, Patel BD, Hinchliffe SJ, et al. Siblings of patients with severe chronic obstructive pulmonary disease have a significant risk of airflow obstruction. Am J Respir Crit Care Med 2001;164:1419-24.

3. Patel BD, Coxson HO, Pillai SG, et al. Airway wall thickening and emphysema show independent familial aggregation in COPD. Am J Respir Crit Care Med 2008;178:500-5.

4. Wacholder S, Chanock S, Garcia-Closas M, et al. Assessing the probability that a positive report is false: an approach for molecular epidemiology studies. J Natl Cancer Inst 2004;96:434-42.

5. Corbett E, Glaisyer H, Chan C, et al. Congenital cutis laxa with a dominant inheritance and early onset emphysema. Thorax 1994;49:836-7.

6. Urban Z, Gao J, Pope FM, et al. Autosomal dominant cutis laxa with severe lung disease: synthesis and matrix deposition of mutant tropoelastin. $J$ Invest Dermatol 2005; 124:1193-9.

7. Kelleher CM, Silverman EK, Broekelmann T, et al. A functional mutation in the terminal exon of elastin in severe, early-onset chronic obstructive pulmonary disease. Am J Respir Cell Mol Biol 2005;33:355-62.

8. Hucthagowder V, Sausgruber N, Kim KH, et al. Fibulin-4: a novel gene for an autosomal recessive cutis laxa syndrome. Am J Hum Genet 2006;78:1075-80.

9. Loeys B, Van Maldergem L, Mortier G, et al. Homozygosity for a missense mutation in fibulin-5 (FBLN5) results in a severe form of cutis laxa. Hum Mol Genet 2002:11:2113-8. 
10. Revencu N, Quenum G, Detaille T, et al. Congenital diaphragmatic eventration and bilateral uretero-hydronephrosis in a patient with neonatal Marfan syndrome caused by a mutation in exon 25 of the FBN1 gene and review of the literature. Eur J Pediatr 2004; 163:33-7.

11. Shinawi M, Boileau C, Brik R, et al. Splicing mutation in the fibrillin-1 gene associated with neonatal Marfan syndrome and severe pulmonary emphysema with tracheobronchomalacia. Pediatr Pulmonol 2005:39:374-8.

12. Tekin M, Cengiz FB, Ayberkin E, et al. Familial neonatal Marfan syndrome due to parental mosaicism of a missense mutation in the FBN1 gene. Am J Med Genet $A$ 2007;143:875-80.

13. Grange DK, Kaler SG, Albers GM, et al. Severe bilateral panlobular emphysema and pulmonary arterial hypoplasia: unusual manifestations of Menkes disease. Am J Med Genet A 2005;139:151-5.

14. Wu L, Chau J, Young RP, et al. Transforming growth factor-beta1 genotype and susceptibility to chronic obstructive pulmonary disease. Thorax 2004:59:126-9.

15. Celedon JC, Lange C, Raby BA, et al. The transforming growth factor-beta1 (TGFB1) gene is associated with chronic obstructive pulmonary disease (COPD). Hum Mol Genet 2004:13:1649-56.

16. Su ZG, Wen FQ, Feng YL, et al. Transforming growth factor-beta1 gene polymorphisms associated with chronic obstructive pulmonary disease in the Chinese population. Acta Pharmacol Sin 2005;26:714-20.

17. Hersh CP, Demeo DL, Lazarus $\mathrm{R}$, et al. Genetic association analysis of functional impairment in chronic obstructive pulmonary disease. Am J Respir Crit Care Med 2006;173:977-84.

18. van Diemen CC, Postma DS, Vonk JM, et al. Decorin and TGF-beta1 polymorphisms and development of COPD in a general population. Respir Res 2006;7:89.

19. Ogawa $\mathbf{E}$, Ruan J, Connett JE, et al. Transforming growth factor-beta1 polymorphisms, airway responsiveness and lung function decline in smokers. Respir Med 2007;101:938-43

20. Silverman EK, Palmer LJ, Mosley JD, et al. Genomewide linkage analysis of quantitative spirometric phenotypes in severe early-onset chronic obstructive pulmonary disease. Am J Hum Genet 2002;70:1229-39.

21. Sterner-Kock A, Thorey IS, Koli K, et al. Disruption of the gene encoding the latent transforming growth factor-beta binding protein 4 (LTBP-4) causes abnormal lung development, cardiomyopathy, and colorectal cancer. Genes Dev 2002;16:2264-73.

22. Gooptu B, Lomas DA. Polymers and inflammation: disease mechanisms of the serpinopathies. J Exp Med 2008;205:1529-34.

23. Dahl M, Tybjaerg-Hansen $A$, Lange $P$, et al. Change in lung function and morbidity from chronic obstructive pulmonary disease in alpha1-antitrypsin MZ heterozygotes: a longitudinal study of the general population. Ann Intern Med 2002:136:270-9.

24. Hersh CP, Dahl M, Ly NP, et al. Chronic obstructive pulmonary disease in alpha1antitrypsin PI MZ heterozygotes: a meta-analysis. Thorax 2004;59:843-9.

25. Sandford AJ, Weir TD, Spinelli JJ, et al. Z and S mutations of the alpha1-antitrypsin gene and the risk of chronic obstructive pulmonary disease. Am J Respir Cell Mol Biol 1999;20:287-91.

26. Demeo DL, Mariani TJ, Lange C, et al. The SERPINE2 gene is associated with chronic obstructive pulmonary disease. Am J Hum Genet 2006;78:253-64.

27. Zhu G, Warren L, Aponte J, et al. The SERPINE2 gene is associated with chronic obstructive pulmonary disease in two large populations. Am J Respir Crit Care Med 2007:176:167-73.

28. Chappell S, Daly L, Morgan K, et al. The SERPINE2 gene and chronic obstructive pulmonary disease. Am J Hum Genet 2006;79:184-7.

29. Minematsu N, Nakamura $\mathrm{H}$, Tateno $\mathrm{H}$, et al. Genetic polymorphism in matrix metalloproteinase-9 and pulmonary emphysema. Biochem Biophys Res Commun 2001;289:116-9

30. Zhou M, Huang SG, Wan HY, et al. Genetic polymorphism in matrix metalloproteinase- 9 and the susceptibility to chronic obstructive pulmonary disease in Han population of south China. Chin Med J (Engl) 2004;117:1481-4.

31. Ito I, Nagai S, Handa $T$, et al. Matrix metalloproteinase-9 promoter polymorphism associated with upper lung dominant emphysema. Am J Respir Crit Care Med 2005; 172:1378-82.

32. Joos $\mathbf{L}, \mathrm{He} J \mathrm{~J}$, Shepherdson MB, et al. The role of matrix metalloproteinase polymorphisms in the rate of decline in lung function. Hum Mol Genet 2002:11:569-76.

33. Tesfaigzi Y, Myers OB, Stidley CA, et al. Genotypes in matrix metalloproteinase 9 are a risk factor for COPD. Int J COPD 2006;1:267-78.

34. Hirano K, Sakamoto T, Uchida Y, et al. Tissue inhibitor of metalloproteinases-2 gene polymorphisms in chronic obstructive pulmonary disease. Eur Respir J 2001;18:748-52.

35. Smith CA, Harrison DJ. Association between polymorphism in gene for microsomal epoxide hydrolase and susceptibility to emphysema. Lancet 1997:350:630-3.

36. Korytina GF, lanbaeva DG, Viktorova TV. [Role of polymorphic variants of cytochrome P450 genes (CYP1A1, CYP2E1) and microsomal epoxide hydrolase (mEPHX) in pathogenesis of cystic fibrosis and chronic respiratory tract diseases] Mol Biol (Mosk) 2003;37:784-92.

37. Cheng SL, Yu CJ, Chen CJ, et al. Genetic polymorphism of epoxide hydrolase and glutathione S-transferase in COPD. Eur Respir J 2004;23:818-24.

38. Fu WP, Sun C, Dai LM, et al. Relationship between COPD and polymorphisms of HOX-1 and mEPH in a Chinese population. Oncol Rep 2007:17:483-8.

39. Hersh CP, Demeo DL, Lange C, et al. Attempted replication of reported chronic obstructive pulmonary disease candidate gene associations. Am J Respir Cell Mol Biol 2005;33:71-8.

40. Matheson MC, Raven J, Walters EH, et al. Microsomal epoxide hydrolase is not associated with COPD in a community-based sample. Hum Biol 2006;78:705-17.
41. Park JY, Chen L, Wadhwa N, et al. Polymorphisms for microsomal epoxide hydrolase and genetic susceptibility to COPD. Int J Mol Med 2005;15:443-8.

42. Sandford AJ, Chagani T, Weir TD, et al. Susceptibility genes for rapid decline of lung function in the lung health study. Am J Respir Crit Care Med 2001;163:469-73.

43. Takeyabu K, Yamaguchi E, Suzuki I, et al. Gene polymorphism for microsomal epoxide hydrolase and susceptibility to emphysema in a Japanese population. Eur Respir J 2000:15:891-4.

44. Xiao D, Wang C, Du MJ, et al. Relationship between polymorphisms of genes encoding microsomal epoxide hydrolase and glutathione S-transferase P1 and chronic obstructive pulmonary disease. Chin Med J (Engl) 2004;117:661-7.

45. Yim JJ, Park GY, Lee CT, et al. Genetic susceptibility to chronic obstructive pulmonary disease in Koreans: combined analysis of polymorphic genotypes for microsomal epoxide hydrolase and glutathione S-transferase M1 and T1. Thorax 2000;55:121-5

46. Yoshikawa M, Hiyama K, Ishioka S, et al. Microsomal epoxide hydrolase genotypes and chronic obstructive pulmonary disease in Japanese. Int J Mol Med 2000;5:49-53.

47. Brogger J, Steen VM, Eiken HG, et al. Genetic association between COPD and polymorphisms in TNF, ADRB2 and EPHX1. Eur Respir J 2006;27:682-8.

48. DeMeo DL, Hersh CP, Hoffman EA, et al. Genetic determinants of emphysema distribution in the national emphysema treatment trial. Am J Respir Crit Care Med 2007; 176:42-8

49. Ishii T, Matsuse T, Teramoto $S$, et al. Glutathione S-transferase P1 (GSTP1) polymorphism in patients with chronic obstructive pulmonary disease. Thorax 1999;54:693-6.

50. He Jo, Ruan J, Connett JE, et al. Antioxidant gene polymorphisms and susceptibility to a rapid decline in lung function in smokers. Am J Respir Crit Care Med 2002;166:323-8.

51. Rodriguez F, de la Roza C, Jardi R, et al. Glutathione S-transferase P1 and lung function in patients with alpha1-antitrypsin deficiency and COPD. Chest 2005:127:1537-43

52. Yamada N, Yamaya M, Okinaga S, et al. Microsatellite polymorphism in the heme oxygenase-1 gene promoter is associated with susceptibility to emphysema. Am J Hum Genet 2000:66:187-95.

53. Nakayama K, Kikuchi A, Yasuda H, et al. Heme oxygenase-1 gene promoter polymorphism and decline in lung function in Japanese men. Thorax 2006;61:921.

54. Budhi A, Hiyama K, Isobe T, et al. Genetic susceptibility for emphysematous changes of the lung in Japanese. Int $\mathrm{J}$ Mol Med 2003;11:321-9.

55. Fu WP, Zhao ZH, Fang LZ, et al. Heme oxygenase-1 polymorphism associated with severity of chronic obstructive pulmonary disease. Chin Med J (Engl) 2007; 120:12-6

56. Juul K, Tybjaerg-Hansen A, Marklund S, et al. Genetically increased antioxidative protection and decreased chronic obstructive pulmonary disease. Am J Respir Crit Care Med 2006:173:858-64.

57. Young RP, Hopkins R, Black PN, et al. Functional variants of antioxidant genes in smokers with COPD and in those with normal lung function. Thorax 2006:61:394-9.

58. Huang SL, Su CH, Chang SC. Tumor necrosis factor-alpha gene polymorphism in chronic bronchitis. Am J Respir Crit Care Med 1997;156:1436-9.

59. Higham MA, Pride NB, Alikhan A et al. Tumour necrosis factor-alpha gene promoter polymorphism in chronic obstructive pulmonary disease. Eur Respir J 2000;15:281-4.

60. Ishii T, Matsuse T, Teramoto S, et al. Neither IL-1beta, IL-1 receptor antagonist, nor TNF-alpha polymorphisms are associated with susceptibility to COPD. Respir Med 2000;94:847-51.

61. Ferrarotti I, Zorzetto M, Beccaria $\mathrm{M}$, et al. Tumour necrosis factor family genes in a phenotype of COPD associated with emphysema. Eur Respir J 2003;21:444-9.

62. Patuzzo C, Gile LS, Zorzetto M, et al. Tumor necrosis factor gene complex in COPD and disseminated bronchiectasis. Chest 2000;117:1353-8.

63. Seifart C, Plagens A, Dempfle A, et al. TNF-alpha, TNF-beta, IL-6, and IL-10 polymorphisms in patients with lung cancer. Dis Markers 2005;21:157-65.

64. Chierakul N, Wongwisutikul P, Vejbaesya S, et al. Tumor necrosis factor-alpha gene promoter polymorphism is not associated with smoking-related COPD in Thailand. Respirology 2005:10:36-9.

65. Hegab AE, Sakamoto T, Saitoh W, et al. Polymorphisms of TNFalpha, IL1beta, and IL1RN genes in chronic obstructive pulmonary disease. Biochem Biophys Res Commun 2005:329:1246-52.

66. Tanaka G, Sandford AJ, Burkett K, et al. Tumour necrosis factor and lymphotoxin A polymorphisms and lung function in smokers. Eur Respir J 2007:29:34-41.

67. Ruse CE, Hill MC, Tobin M, et al. Tumour necrosis factor gene complex polymorphisms in chronic obstructive pulmonary disease. Respir Med 2007;101:340-4.

68. Papatheodorou A, Latsi P, Vrettou C, et al. Development of a novel microarray methodology for the study of SNPs in the promoter region of the TNF-alpha gene: their association with obstructive pulmonary disease in Greek patients. Clin Biochem 2007:40:843-50

69. Kueppers F, Miller RD, Gordon $\mathrm{H}$, et al. Familial prevalence of chronic obstructive pulmonary disease in a matched pair study. Am J Med 1977:63:336-42.

70. Horne SL, Cockcroft DW, Dosman JA. Possible protective effect against chronic obstructive airways disease by the GC2 allele. Hum Hered 1990;40:173-6.

71. Schellenberg D, Pare PD, Weir TD, et al. Vitamin D binding protein variants and the risk of COPD. Am J Respir Crit Care Med 1998;157:957-61.

72. Ishii T, Keicho N, Teramoto $\mathrm{S}$, et al. Association of Gc-globulin variation with susceptibility to COPD and diffuse panbronchiolitis. Eur Respir J 2001;18:753-7.

73. Ito I, Nagai S, Hoshino Y, et al. Risk and severity of COPD is associated with the group-specific component of serum globulin $1 \mathrm{~F}$ allele. Chest 2004:125:63-70. 
74. Kasuga I, Pare PD, Ruan J, et al. Lack of association of group specific component haplotypes with lung function in smokers. Thorax 2003;58:790-3.

75. Parmar JS, Mahadeva R, Reed BJ, et al. Polymers of alpha(1)-antitrypsin are chemotactic for human neutrophils: a new paradigm for the pathogenesis of emphysema. Am J Respir Cell Mol Biol 2002;26:723-30.

76. Mulgrew AT, Taggart CC, Lawless MW, et al. Z alpha1-antitrypsin polymerizes in the lung and acts as a neutrophil chemoattractant. Chest 2004:125:1952-7.

77. Chappell S, Daly L, Morgan K, et al. Cryptic haplotypes of SERPINA1 confer susceptibility to chronic obstructive pulmonary disease. Hum Mutat 2006;27:103-9.
78. Keatings VM, Cave SJ, Henry MJ, et al. A polymorphism in the tumor necrosis factor-alpha gene promoter region may predispose to a poor prognosis in COPD. Chest 2000;118:971-5.

79. Sakao S, Tatsumi K, Igari $\mathrm{H}$, et al. Association of tumor necrosis factor alpha gene promoter polymorphism with the presence of chronic obstructive pulmonary disease. Am J Respir Crit Care Med 2001;163:420-2.

80. Kucukaycan M, Van Krugten M, Pennings HJ, et al. Tumor necrosis factor-alpha $+489 \mathrm{G} / \mathrm{A}$ gene polymorphism is associated with chronic obstructive pulmonary disease. Respir Res 2002:3:29

\section{Pulmonary puzzle}

\section{ANSWER}

From the question on page 290

The total white cell count of the BAL fluid was $184 / \mathrm{mm}^{3}$ with $54 \%$ eosinophils. Figure 1 shows clusters of granulated and degranulated eosinophils within a background of septal oedema. Comprehensive examination of the BAL fluid and biopsy material yielded no clear infectious cause. These findings are consistent with a diagnosis of acute eosinophilic pneumonia (AEP), which is characterised by progressive respiratory symptoms, diffuse bilateral infiltrates and increased numbers of lung eosinophils in the absence of detectable infection. ${ }^{1}$ Biopsy, although not necessary for diagnosing AEP, may be useful for ruling out other causes of pulmonary eosinophilia. Other entities to consider in patients with acute progressive respiratory symptoms and increased numbers of eosinophils in the BAL fluid include drug reactions and fungal and parasitic infections.

The clinical course typically begins with fever averaging $38^{\circ} \mathrm{C}$, cough, tachypnoea, hypoxaemia and dyspnoea and often progresses rapidly. Plain radiographs may show an interstitial, alveolar or mixed pattern and pleural effusions are common. ${ }^{12}$ Environmental, occupational and recreational exposures are thought to play a significant role in the pathogenesis of AEP. A number of authors have described the development of AEP shortly after the onset of smoking. ${ }^{13} 4$ AEP has also been reported in a patient who became symptomatic shortly after participating in a bicycle race "in dusty conditions". ${ }^{5}$ Our patient had both exposures, as he later admitted to trying cigarette smoking for the first time the evening before his symptoms developed.

At presentation the patient had increased peripheral blood neutrophils, a phenomenon previously reported in cigarette smoke-induced AEP. ${ }^{4}$ While peripheral blood eosinophilia characteristically does not occur during the acute phase of AEP, levels may become quite high during convalescence before normalising. ${ }^{2}$ The patient's peripheral blood absolute eosinophil count was $1380 / \mathrm{mm}^{3} 1$ week after discharge. On rechecking 5 months later, it had returned to the normal range.

While individuals with AEP classically show clinical improvement after the initiation of steroids, most who are treated with only supportive measures also recover completely. ${ }^{2}$ Although case reports have described the return of symptoms upon re-exposure to an inciting factor, ${ }^{3}$ most patients develop tolerance and do not have recurrence. ${ }^{12}$ We advised our patient to avoid cigarette smoke altogether. His symptoms resolved completely with no lasting pulmonary function abnormalities after a course of steroids.

Acknowledgements: The authors wish to thank Dr Rubin Tuder for his assistance with obtaining the histological image Thorax 2009:64:364. doi:10.1136/thx.2008.100503a

\section{REFERENCES}

1. Allen J. Acute eosinophilic pneumonia. Semin Respir Crit Care Med 2006;27:142-7.

2. Philit F, Etienne-Mastroianni B, Parrot A, et al. Idiopathic acute eosinophilic pneumonia: a study of 22 patients. Am J Respir Crit Care Med 2002;166:1235-9.

3. Watanabe K, Fujimura M, Kasahara K, et al. Acute eosinophilic pneumonia following cigarette smoking: a case report including cigarette-smoking challenge test. Intern Med 2002;41:1016-20.

4. Miki K, Miki M, Nakamura Y, et al. Early-phase neutrophilia in cigarette smoke-induced acute eosinophilic pneumonia. Intern Med 2003:42:839-45

5. Badesch DB, King TE Jr, Schwarz MI. Acute eosinophilic pneumonia: a hypersensitivity phenomenon? Am Rev Respir Dis 1989;139:249-52. 